\title{
Hyperlipidemia impairs uterine $\beta$-adrenergic signaling by reducing CAMP in late pregnant rats
}

\author{
Sakshi Chauhan, Subhashree Parida, E Prakash¹, G Srinivasan¹, Vivek Srivastava', \\ Manjit Panigrahi ${ }^{2}$, Thakur Uttam Singh ${ }^{1}$ and Santosh K Mishra ${ }^{1}$ \\ ${ }^{1}$ Division of Pharmacology and Toxicology, ICAR-Indian Veterinary Research Institute, Bareilly, India and ${ }^{2}$ Division of \\ Animal Genetics and Breeding, ICAR-Indian Veterinary Research Institute, Bareilly, India \\ Correspondence should be addressed to S Parida; Email: subhaparida1210@gmail.com
}

\begin{abstract}
The aim of the present study was to reveal the effect of hyperlipidemia on $\beta_{2}$ - and $\beta_{3}$-adrenergic signaling in late pregnant rat uterus. Hyperlipidemia was induced in female Wistar rats by feeding a high-fat high-cholesterol diet for 8 weeks before and after mating upto the 21st day of gestation. The effect of hyperlipidemia on $\beta$-adrenergic signaling was studied with the help of tension experiments, real-time PCR and cAMP ELISA in 21-day pregnant rat uterus. In tension experiments, hyperlipidemia neither altered the spontaneous contractility nor the oxytocin-induced contractions. However, it decreased the $-\operatorname{logEC}_{50}$ values of $\beta_{2}$-adrenoceptor agonist, salbutamol and $\boldsymbol{\beta}_{3}$-adrenoceptor agonist, BRL37344. It also decreased the efficacy of adenylyl cyclase activator, forskolin. Further, there was a significant decrease in salbutamol and BRL37344-stimulated cAMP content in uterine tissues. However, there was no alteration in mRNA expressions of $\beta_{2}$-adrenoceptor (Adrb2), $\beta_{3}$-adrenoceptor (Adrb3) and Gs protein (Gnas) though there was a significant increase in the mRNA expression of Gi protein (Gnai). In conclusion, reduced cAMP content after beta-adrenergic receptor stimulation, which correlates with an increase in Gnai mRNA, may explain the mechanism of the impairment of uterine $\beta$-adrenergic signaling in hyperlipidemic pregnant rats. The clinical implication of the present study may relate to reduced myometrial relaxant response to $\beta$-adrenergic agonists in high fat-induced uterine dysfunction.

Reproduction (2020) 159 49-58
\end{abstract}

\section{Introduction}

Hyperlipidemia is a normal maternal adaptation in pregnancy. However, altered lipid metabolism beyond the physiological limits leads to numerous pregnancyrelated complications. Alteration in lipid metabolism is a common feature of obesity as well and is associated with elevated cholesterol and triglyceride levels. Elevated cholesterol level has been linked to reduced membrane fluidity (Subczynski et al. 2017), altered cellular signaling (Sheng et al. 2012) and membrane hyperpolarization (Shmygol et al. 2007). All these together could contribute to defective uterine contractility and can cause failure in induction or progress of labor (AISaif et al. 2015).

High triglyceride levels, however, can have contradicting effects increasing the risk of spontaneous preterm delivery (Lin et al. 2018). Moreover, women who have moderately elevated serum free fatty acids independent of BMI show a greater risk of preterm delivery (Chen \& Scholl 2008). In our previous effort we created a model of hypercholesterolemia in mouse, where oxytocin response in term pregnancy was significantly hampered (Padol et al. 2017). However, since obesity is characterized by elevated triglycerides along with cholesterol, we were interested to study the effect of hyperlipidemia (elevation of both cholesterol and triglycerides) on uterine contractile and relaxant pathways.

$\beta$-Adrenergic receptors are inhibitory in nature and have control over uterine smooth muscle tone. Controlled uterine contractility is essential for transport of semen to oviduct in non-pregnant uterus and correct embryo position and spacing in early pregnant animals. Both $\beta_{2}$ and $\beta_{3}$-adrenergic receptors are stimulated in non-pregnant human myometrium to elicit concentration-related relaxation (Pedzińska-Betiuk et al. 2011). Transient activation of $\beta_{2}$-adrenergic receptors in 4th day pregnant mice disrupts embryo spacing and leads to implantation failure (Chen et al. 2011). Uterine quiescence leading to distension and adaptation for the developing fetus in mid-stage of gestation is attributed to increased $\beta_{2}$-adrenoreceptor function (Engstrøm et al. 1997). Downregulation of these receptors at term contributes to the removal of uterine quiescence (Chanrachakul et al. 2003). Further, $\beta_{2}$-adrenoreceptor agonists such as ritodrine and salbutamol are clinically used in the treatment of preterm labor (De Heus et al. 2009).

$\beta_{3}$-Isoforms are predominant over the $\beta_{2}$-adrenergic receptor subtype in human myometrium (Rouget et al. 
2005) unlike mouse myometrium (Parida et al. 2013). Furthermore, $\beta_{3}$-adrenergic receptors are resistant to the long-term agonist-induced desensitization of the human myometrium at the end of pregnancy (Rouget et al. 2004). The expression of $\beta_{3}$-adrenoceptors in the human myometrium near term is high, where its stimulation with a selective agonist induces a cAMP-dependent relaxation via a Gs protein coupling. Moreover, $\beta_{3^{-}}$ adrenergic receptor stimulation also inhibited cytokine production (such as TNF $\alpha$, IL-6, and IL-8) to prevent myometrial cell apoptosis (Lirussi et al. 2008) as well as extracellular matrix remodeling (Lirussi et al. 2010), two common features associated with uterine preparation for labor onset. Therefore, the $\beta_{3}$-adrenoceptor stimulation plays a protective role against preterm labor by blocking myometrial contraction, cytokine production, remodeling and apoptosis.

$\beta$-Adrenergic receptors' expression as well as activity decline in late pregnancy with the highest reduction at term to facilitate labor. Moreover, $\beta$-adrenergic receptors are known to be allosterically modulated by lipids particularly cholesterol, limiting their conformational variability (Manna et al. 2016). We hypothesized that lipids may be regulating the inhibitory $\beta$-adrenergic signaling at the functional, as well as molecular levels to cause uterine dysfunctions in late pregnancy. Hence the objective of this study was to investigate the effect of hyperlipidemia on $\beta_{2}$ and $\beta_{3}$-adrenergic signaling as well as on the transcriptional regulation of $\beta_{2}$ and $\beta_{3}$-adrenoceptors, Gs and Gi proteins in the late pregnant rat uterus.

\section{Materials and methods}

\section{Animals and diet}

All animal procedures employed in the study were approved by the Institutional Animal Ethics Committee at Indian Veterinary Research Institute (approval no. F.1-53/2012$13 / J D(R)$ dated 05.03.2015) and all rats and fetuses were humanely killed. Recently weaned female Wistar rats of about 150-200 g weight were procured from the Laboratory Animal Resource Section of the Institute and group housed (two per cage) under standard laboratory conditions as outlined in CPCSEA (Committee for the Purpose of Control and Supervision of Experiments on Animals) guidelines. After an acclimatization period of 7 days, rats were randomly assigned to control and hyperlipidemia groups and fed standard rodent diet and high-fat high-cholesterol (HFHC) diet, respectively. The HFHC feed composition is given in Table 1. The diet was based on the composition of a commercial diet available from Research Diets Inc. (Product \#D12451) with some modification. Composition of cholesterol and cholic acid was adopted from previously published high-cholesterol diet (Padol et al. 2017). HFHC diet was prepared fresh daily and the feed remaining from the previous day feeding was removed from the cage before providing fresh feed and water ad lib to the animals.
Table 1 High-fat high-cholesterol diet composition.

\begin{tabular}{lcc}
\hline Ingredient & Weight $(\mathrm{g})$ & Energy $(\mathrm{kcal})$ \\
\hline Standard chow & 40.0 & $167.03(42.7 \%)$ \\
Lard & 17.4 & $156.60(40 \%)$ \\
Sucrose & 17.0 & $66.98(17.1 \%)$ \\
Total & 74.4 & $390.61(5.25 \mathrm{kcal} / \mathrm{g})$ \\
\hline
\end{tabular}

Cholesterol and cholic acid were added to the above diet @1.25\% and $0.75 \%$, respectively.

\section{Pregnancy induction}

Rats from both the groups were fed their respective diets for the pre-mating period of 8 weeks. On day 56 rats were mated with same age group males in the ratio of 1:1. The animals were housed with males overnight (kept for mating at 18:00 h) and the mating used to be confirmed at $6: 00 \mathrm{~h}$ on the next day. If no mating was confirmed, the animals used to be separated until night. The mating time used to be noted as 0.5 day post coitus in the next day morning at 6:00 h. All the animals underwent successful mating within 7 days of cohabitation. Mating was confirmed through the appearance of spermatozoa in vaginal smear under light microscope. Following mating, pregnant females were separated from males and maintained on their respective diet until parturition. Weekly body weight of all the animals was recorded during pre-mating and gestation period. To know the effect of long-term feeding of high-fat high-cholesterol diet on the duration of gestation, the time of parturition was also recorded in some animals of both control and hyperlipidemia groups.

\section{Sample collection}

On day 21 of gestation, blood was collected under urethane anesthesia from retro-orbital plexus through capillary tube in microfuge tubes and later serum was separated for estimation of cholesterol and triglyceride levels. The animals were killed before the onset of labor by cervical dislocation under urethane anesthesia (@1-1.2 g/kg I.P.). After killing, renal and peritoneal adipose tissue depots from both groups of animals were carefully dissected and weighed. Total number of foetuses in control and hyperlipidemia groups were also counted and weighed after removing fetal membranes. The uterus was dissected and collected in ice cold Modified Kreb's-Henseleit solution (MKHS; pH 7.4). Adhering fat and tissue were cleaned and uterine tissues from the same region of the uterine horn in all animals were collected and stored in refrigerator at $4{ }^{\circ} \mathrm{C}$ in MKHS for further use in tension experiments. The uterine tissues were also harvested and stored at $-80^{\circ} \mathrm{C}$ for analysis of total cholesterol and triglycerides content. Additionally, some uterine samples were stored in RNAlater ${ }^{\mathrm{TM}}$ (Qiagen) to protect them from RNase for use in mRNA expression studies.

\section{Lipid profile}

Total cholesterol and triglycerides in the serum and uterine tissue were estimated through commercially available kits (Coral Clinical Systems, India) following manufacturer's instructions. For serum sample, $10 \mu \mathrm{L}$ of sample and standard (provided in kit) were used in duplicate to which $1 \mathrm{~mL}$ of 
working reagent was added. The samples were kept for incubation at $37^{\circ} \mathrm{C}$ for $10 \mathrm{~min}$. The spectrophotometric readings were taken at $505 \mathrm{~nm}$ wavelength. The values were expressed as $\mathrm{mg} / \mathrm{dL}$ of serum. In uterine tissues, cholesterol and triglycerides content were estimated according to the lipid extraction methodologies previously described by Padol et al. (2017). In brief, approximately $100 \mathrm{mg}$ of pre-stored tissue was taken in $500 \mu \mathrm{L}$ of isopropanol/hexane $(2: 3 \mathrm{v} / \mathrm{v})$ mixture. Tissues were homogenized and further centrifuged at $2000 \mathrm{~g}$ at $25^{\circ} \mathrm{C}$ for $10 \mathrm{~min}$. After centrifugation the upper liquid phase was evaporated at $37^{\circ} \mathrm{C}$ under nitrogen and residual lipid film was resuspended in $1 \mathrm{~mL}$ of ethyl acetate. Further tissue cholesterol and triglycerides were estimated by the protocol as described for the serum. The values were expressed as $\mathrm{mg} / \mathrm{g}$ tissue.

\section{Isometric tension experiments}

Longitudinal uterine strips $(6-8 \times 2-3 \mathrm{~mm})$ from the midhorn region were mounted between two loops made from 37 gauge stainless steel wire in a thermostatically controlled isolated $10 \mathrm{~mL}$ organ bath (Ugo Basile, Italy) containing MKHS which was continuously bubbled with medical gas $\left(21 \% \mathrm{O}_{2}+5 \% \mathrm{CO}_{2}+74 \% \mathrm{~N}_{2}\right)$ maintained at $37 \pm 1^{\circ} \mathrm{C}$ under a constant passive tension of $0.7 \mathrm{~g}$ throughout the experiment. The uterine strips were washed every $15 \mathrm{~min}$ and equilibrated until they produced regular spontaneous rhythmic contractile activity. Isometric contractions were recorded by means of a high sensitivity force displacement transducer (Model: MTL 0202/D, Power Lab, Australia) connected to a computer using the chart v4.1.2 software program (Power Lab, Australia).

\section{Experimental protocols for tension experiments}

\section{Assessment of the effect of hyperlipidemia on spontaneous uterine contractions at term}

After equilibration of uterine tissue of rats for 60 min with MKHS, the normal spontaneous contractions were recorded. The frequency (contractions/min) and amplitude (gram tension) were determined and mean integral tension (MIT) was calculated as described elsewhere (Singh et al. 2015).

\section{Assessment of the effect of hyperlipidemia on oxytocin-induced uterine contractions}

After recording the basal spontaneous uterine activity in both the groups, response to oxytocin was assessed by its in vitro addition into bath solution. After equilibration of uterine tissue for $1 \mathrm{~h}$ in MKHS, concentration-dependent responses to oxytocin $\left(10^{-12}-10^{-6} \mathrm{M}\right)$ were elicited.

\section{Assessment of the effect of hyperlipidemia on concentration-dependent response to $\beta_{2}$-adrenoceptor agonist, salbutamol in isolated uterine tissue}

The tissue strips from both the groups were equilibrated for $60-90 \mathrm{~min}$ in MKHS until stable contractions were attained. Response to salbutamol $\left(10^{-11}-10^{-5} \mathrm{M}\right)$ was assessed over the basal contraction by its in vitro addition to the bath solution.

\section{Assessment of the effect of hyperlipidemia on concentration-dependent response to $\beta_{3}$-adrenoreceptor agonist, BRL37344 in isolated uterine tissue}

After equilibrating the pregnant rat uterine strips for 60-90 min in MKHS, response to $\beta_{3}$-adrenoreceptor agonist, BRL37344 $\left(10^{-11}-10^{-5} \mathrm{M}\right)$ was elicited in both the groups.

\section{Assessment of the effect of hyperlipidemia on concentration-dependent response to forskolin in isolated uterine tissue}

Forskolin is an activator of adenylyl cyclase which increases the concentration of intracellular cAMP. After equilibration in MKHS for $60 \mathrm{~min}$, concentration-dependent response to forskolin $\left(10^{-11}-10^{-5} \mathrm{M}\right)$, was assessed.

\section{CAMP estimation}

Basal and $\beta$-adrenergic agonist that is salbutamol and BRL47344-stimulated uterine cAMP concentrations were assayed by commercially available kit (Cayman Chemicals) following the manufacturer's instructions.

Uterine strips from the late pregnant rats weighing approximately $100 \mathrm{mg}$ were tied with thread and carefully transferred into test tubes containing MKHS. The test tubes were placed in a water bath $\left(37^{\circ} \mathrm{C}\right)$ and the myometrial tissues were constantly aerated. The phosphodiesterase activity was inhibited by treatment of myometrial strips with $10 \mathrm{mM}$ IBMX which is a non-specific phosphodiesterase inhibitor. At the end of equilibration period $(30 \mathrm{~min})$, the myometrial strips were stimulated with salbutamol $(1 \mu \mathrm{M})$ and BRL $(10 \mu \mathrm{M})$ for a period of $5 \mathrm{~min}$. After this brief stimulation, the myometrial strips were dipped in liquid nitrogen and immediately homogenized in $1.5 \mathrm{~mL}$ of $6 \% \mathrm{TCA}$ at $4^{\circ} \mathrm{C}$. The samples, those were used for the estimation of basal activity were also processed similarly, but did not receive any drug treatment. The homogenized samples were transferred into fresh centrifuge tubes and centrifuged for $10 \mathrm{~min}$ at $10,000 \mathrm{~g}$ at $4^{\circ} \mathrm{C}$ in order to discard high-molecular-weight components and denatured proteins. The acidic supernatant was decanted into separate tubes. The acidic TCA was also extracted from the sample by using water saturated ether. For making water saturated ether, water was added to ether until layers formed. Top layer of ether was used for further procedures. Five volumes of ether were used for one volume of sample. It was mixed for $10 \mathrm{~s}$, when organic and aqueous phases were separated then top layer was carefully removed and discarded. Extraction with ether was repeated for two times. After that, residual ether was removed from aqueous layer by heating the sample to $70^{\circ} \mathrm{C}$ for $5 \mathrm{~min}$. Complete ether was removed from the sample as it causes interference with assay. Samples were then stored at $-20^{\circ} \mathrm{C}$ till further processing for CAMP estimation by indirect ELISA kit (Cayman Chemical) by following the manufacturer's instructions. The pelleted material was immediately used for the estimation of protein by Bradford protein assay kit $\left(\mathrm{GeNei}^{\mathrm{TM}}\right.$, Bangalore, India) according to the manufacturer's instructions. 


\section{Real-time PCR}

We employed real-time PCR technique to examine the relative mRNA expressions of Adrb2, Adrb3, Gnas, Gnai in the uterus of control and HFHC diet-fed dams. Total RNA was isolated using the RNeasy Plus Mini Kit (Qiagen) as per the manufacturer's instructions. The purity of the RNA was checked by A260/A280 ratio and A230/A260 ratio in a nanodrop and quantified as $1 \mathrm{OD}=40 \mu \mathrm{g} / \mathrm{mL}$. cDNA was synthesized using High-Capacity RNA-to-cDNA Kit (Applied Biosystems). Realtime PCR was conducted using Fast SYBR Green Master mix (Applied Biosystems). Each sample was run in triplicate in a 25 $\mu \mathrm{L}$-reaction consisting 12.5 $\mu \mathrm{L}$ SYBR Green master mix, $1 \mu \mathrm{L}$ of $10 \mathrm{pM}$ stock solution of each of gene-specific forward and reverse primers, $1 \mu \mathrm{L}$ of cDNA and volume was made up to $25 \mu \mathrm{L}$ with RNAse-free water. The specific primer sequences have been given in Table 2 . The real-time PCR reaction started with an initial incubation at $95^{\circ} \mathrm{C}$ for $10 \mathrm{~min}$, followed by 35 cycles of amplification with denaturation at $95^{\circ} \mathrm{C}$ for 35 $\mathrm{s}$, annealing at $57^{\circ} \mathrm{C}$ for $30 \mathrm{~s}$ and extension at $72^{\circ} \mathrm{C}$ for $30 \mathrm{~s}$. The result was expressed as threshold cycle values $\left(C_{T}\right)$. The threshold automatically adjusted by the instrument was used for the generation of $C_{\mathrm{T}}$ values. Rat $\beta$-actin (Actb) was used as the housekeeping gene (endogenous control) for the analysis of data.

\section{Drugs}

Salbutamol, BRL-37344, forskolin, were purchased from Sigma-Aldrich. Oxytocin was from Anaspec, USA. DMSO served as a vehicle for forskolin. Stock solutions of oxytocin, salbutamol and BRL-37344 were prepared in distilled water, stored at $-20^{\circ} \mathrm{C}$ and dilutions were prepared in MKHS just before use. DMSO at the concentrations used was checked to have little effect on the responses of the tissue.

\section{Statistical analysis}

Contractile responses to oxytocin were expressed as the percentage of MIT of preceding spontaneous contraction response (set at 100\%). Relaxant responses to salbutamol, BRL-37344, and forskolin, were expressed as \% control relaxation (set at $0 \%$ ). Nonlinear regression analysis (sigmoidal dose-response) was used to determine the $\mathrm{E}_{\max }$ (the maximal response) and $\mathrm{EC}_{50}$ (the concentration producing $50 \%$ of the maximal response) of agonists by Graph Pad Prism, version 6 software. Results have been expressed as the mean \pm S.E.M. with $n$ equal to the number of animals. Two-way ANOVA was used for comparison of concentration-responses between two groups.
To study the relative change in gene expression, the difference in $C_{T}$ values for the gene of interest and the endogenous control was calculated $\left(\Delta \mathrm{C}_{\mathrm{T}}\right)$ for each group. The negative value of this subtraction, the $-\Delta C_{T}$, was used as the exponent of 2 and represented the 'corrected' number of cycles to threshold. The data were expressed as $2^{-\Delta C T}$ values in both the groups (Schmittgen \& Livak 2008, Gokul et al. 2018). Student's ' $t$ '-test was employed for comparison of means between two groups. cAMP data were analyzed by two-way ANOVA followed by Bonferroni post hoc test for multiple comparisons. $P<0.05$ was considered significant.

\section{Results}

\section{HFHC diet increased cholesterol and triglyceride levels in serum and uterine tissue}

At the end of the gestation period, there was a significantly higher level $(P<0.0001)$ of serum cholesterol (control: $41.2 \pm 6.1 \mathrm{mg} / \mathrm{dL}, n=7$ vs HFHC: $183.7 \pm 22.1 \mathrm{mg} / \mathrm{dL}$, $n=9)$ as well as the triglycerides $(P<0.0001)$ (control: $80.1 \pm 14.5 \mathrm{mg} / \mathrm{dL}, n=6$ vs HFHC: $208.3 \pm 11.1 \mathrm{mg} / \mathrm{dL}$, $n=7)$ in HFHC animals compared to standard diet-fed animals (Fig. 1A). Similar rise in cholesterol (control: $4.01 \pm 1.02 \mathrm{mg} / \mathrm{g}, n=6 \mathrm{vs}$ HFHC: $8.63 \pm 0.37 \mathrm{mg} / \mathrm{g}, n=6$, $P=0.001$ ) and triglyceride levels (control: $7.25 \pm 0.68$ $\mathrm{mg} / \mathrm{g}, n=6$ vs HFHC: $14.06 \pm 1.81 \mathrm{mg} / \mathrm{g}, n=7, P=0.006$ ) was also observed in uterine tissues (Fig. 1B).

\section{Effect of hyperlipidemia on body weight, litter size, pup size, renal and scapular fat of rats as well as length of gestation}

Larger gain in body weight was observed after 8 weeks of feeding in animals of hyperlipidemic group though the same was not altered at the end of gestation (Table 3). Hyperlipidemia also increased the average fetal weight, renal fat and scapular fat content; however, there was no significant effect on the litter sizes of rats (Table 3). Additionally, gestation length was significantly shortened in hyperlipidemic animals (Table 3 ).

\section{Effect of hyperlipidemia on spontaneous and oxytocin-induced uterine activity}

Hyperlipidemia did not alter spontaneous, as well as oxytocin-induced uterine activity. Representative tracings of spontaneous activity are shown in Fig. 2A.

Table 2 Primer sequences used for real-time PCR.

\begin{tabular}{lllcc}
\hline \multirow{2}{*}{ Rat genes } & \multicolumn{2}{c}{ Primer sequence $\left(5^{\prime}-3^{\prime}\right)$} & Amplicon size $($ bp) & Annealing temperature $\left({ }^{\circ} \mathrm{C}\right)$ \\
\cline { 2 - 5 } & Forward & Reverse & 125 & 60 \\
Actb & TCCCTGGAGAAGAGCTATGA & TCATGGATGCCACAGGATTC & 123 & 60 \\
Adrb3 & GCCTATGCTATCGCTTCCT & GCCCTCGGATTTGTCTATCT & 130 & 60 \\
Gnas & GTTTGTGCTGGATGCTTAGG & CAGAGACTGGGAACACAGAA & 131 & 60 \\
Gnai & CTACTGCTACCCTCACTTTACC & TTTGGGCGTTCCCTTCTT & 125 & 60 \\
\hline
\end{tabular}



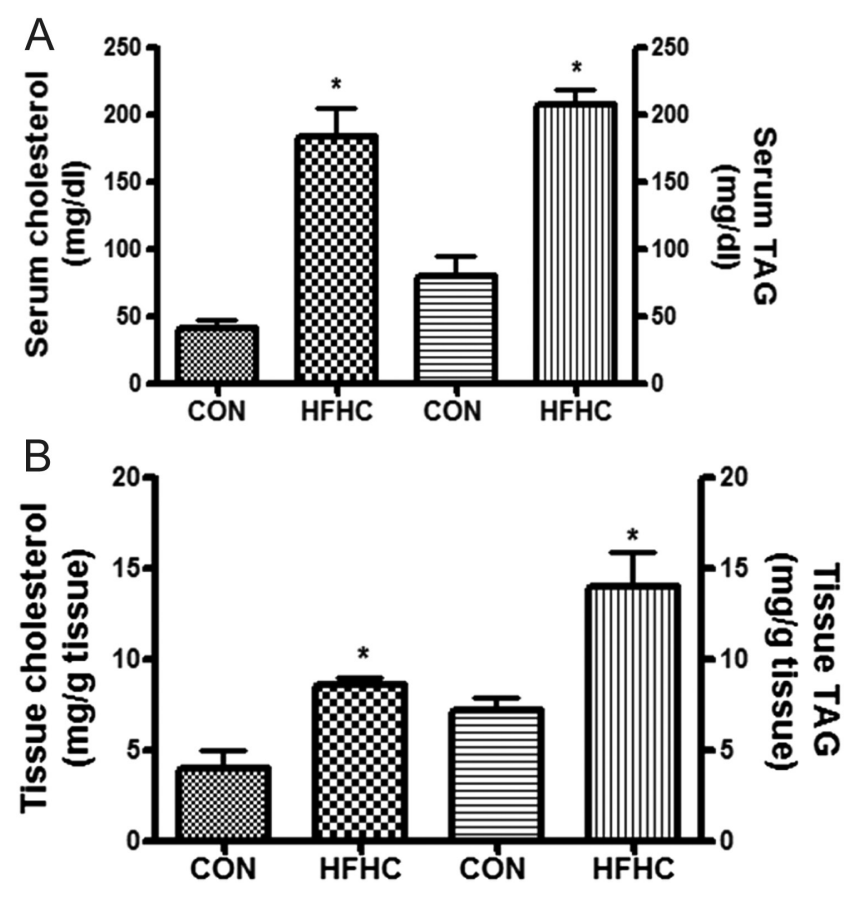

Figure 1 The effects of feeding either a control or HFHC diet for 8 weeks prior to and during pregnancy on the levels of total cholesterol and triglycerides in maternal serum (A) and uterine tissue (B) on 21st day of gestation in rats. Values are means with S.E.M. represented by vertical bars. The data were analyzed by unpaired $t$-test. * indicates $P<0.05$ as compared to cholesterol level and triglyceride level in control rats.

The amplitude of the spontaneous contractions in hyperlipidemic animals $(1.14 \pm 0.12 \mathrm{~g}, n=6-8)$ was significantly higher $(P=0.006)$ than the control animals $(0.69 \pm 0.09 \mathrm{~g}, n=6-8)$. The frequency of the spontaneous contractions in hyperlipidemic animals $(1.53 \pm 0.05$ cycles per min, $n=6-8)$ was significantly lower $(P=0.001)$ than the control animals $(1.91 \pm 0.07$ cycles per min, $n=6-8)$. However, the mean integral tension (corresponding to both amplitude and frequency together in a specified duration) in control animals was $26.71 \pm 5.17$ g per min $(n=6-8)$ which was comparable $(P=0.64)$ with the tension in hyperlipidemic animals
$(29.39 \pm 3.01$ g per min, $n=6-8)$. The contraction amplitude, frequency, and MIT are depicted in the right and lower panels of Fig. 2A. It can be noticed that the amplitude was increased while frequency was decreased in HFHC animals which may explain for no significant alteration in MIT of spontaneous contractions.

The representative tracings in Fig. 2B depict a concentration-dependent increase in contractile responses to oxytocin in the uterus of control and hyperlipidemic late pregnant rats. Oxytocin $\left(10^{-12}\right.$ $\left.10^{-6} \mathrm{M}\right)$, added at an increment of $0.5 \log$ unit caused a concentration-dependent increase in spontaneous rhythmic contractions. The $\mathrm{E}_{\max }$ and $-\log \mathrm{EC}_{50}$ of oxytocin-induced contractions were $352.0 \pm 79.32 \%$ and $7.89 \pm 0.28(n=5)$, respectively in standard dietfed rats. The $\mathrm{E}_{\max }$ and $-\log \mathrm{EC}_{50}$ of oxytocin-induced contractions were $274.5 \pm 44.04 \%$ and $8.40 \pm 0.25$, respectively in the uterus of hyperlipidemic rats. The $\mathrm{E}_{\max }$ and $-\log \mathrm{EC}_{50}$ were not significantly different $(P=0.41$ and 0.21 , respectively) from each other. The concentration response curves to oxytocin were not statistically different $(P=0.09)$ between the two groups.

\section{Effect of hyperlipidemia on salbutamol-induced uterine relaxation}

Salbutamol $\left(10^{-11}-10^{-5} \mathrm{M}\right)$, added cumulatively to uterine strips, produced a concentration-related relaxation. Hyperlipidemia significantly $(P<0.05)$ decreased the $-\operatorname{logEC} C_{50}$ value $(7.61 \pm 0.17 \quad$ vs $8.33 \pm 0.18$ in control) of salbutamol response. Also, the concentration-response to salbutamol was significantly inhibited in hyperlipidemia group $(P=0.005)$. However, there was no significant effect on the $\mathrm{E}_{\max }(93.64 \pm 7.06 \%$ vs $100.8 \pm 8.11 \%$ in control) of the response (Fig. $3 \mathrm{~A}$ ).

\section{Effect of hyperlipidemia on BRL-37344-induced uterine relaxation}

Representative tracings of BRL-37344-induced relaxation are shown in Fig. 3B. $E_{\max }$ of BRL-37344induced relaxation was $105.6 \pm 12.56 \%$ in control

Table 3 Effect of high-fat high-cholesterol diet on body weight, litter size, fetus weight, renal and scapular fat depot and gestational length of late pregnant rats.

\begin{tabular}{lccc}
\hline & Control diet & HFHC diet & P value \\
\hline Initial body weight $(\mathrm{g})$ & $164 \pm 10.9(n=6)$ & $188.8 \pm 6.2(n=12)$ & 0.052 \\
Body weight (g) at the end of 8 weeks feeding & $193 \pm 11.6(n=6)$ & $243.8 \pm 6.0(n=12)$ & $\mathbf{0 . 0 0 0 6}$ \\
Gain in body weight at the end of 8 weeks feeding & $29.1 \pm 7.7(n=6)$ & $24.9 \pm 3.3(n=12)$ & $\mathbf{0 . 0 0 4}$ \\
Body weight (g) at the start of gestation & $194.2 \pm 5.23(n=6)$ & $330.0 \pm 7.07(n=6)$ & $\mathbf{0 . 0 0 0 1}$ \\
Body weight (g) at the end of gestation & $277.5 \pm 8.24(n=6)$ & $85.83 \pm 9.44(n=6)$ & $\mathbf{0 . 0 0 0 7}$ \\
Gain in body weight during gestation & $83.33 \pm 3.58(n=6)$ & $10.00 \pm 1.00(n=6)$ & 0.81 \\
Litter size & $9.67 \pm 1.02(n=6)$ & $3.26 \pm 0.12(n=6)$ & 0.82 \\
Average fetal weight (g) & $2.92 \pm 0.05(n=6)$ & $2.54 \pm 0.08(n=6)$ & $\mathbf{0 . 0 2 9}$ \\
Renal fat (g) & $1.05 \pm 0.09(n=6)$ & $7.57 \pm 0.27(n=6)$ & $<\mathbf{0 . 0 0 0 1}$ \\
Scapular fat (g) & $3.10 \pm 0.18(n=6)$ & $21.45 \pm 0.3(n=5)$ & $\mathbf{0 . 0 0 0 1}$ \\
Length of gestation (days) & $22.15 \pm 0.1(n=6)$ & $\mathbf{0 . 0 4}$ &
\end{tabular}

Data were analyzed by unpaired $t$-test. $P<0.05$ is considered significant and presented in boldface. 
A
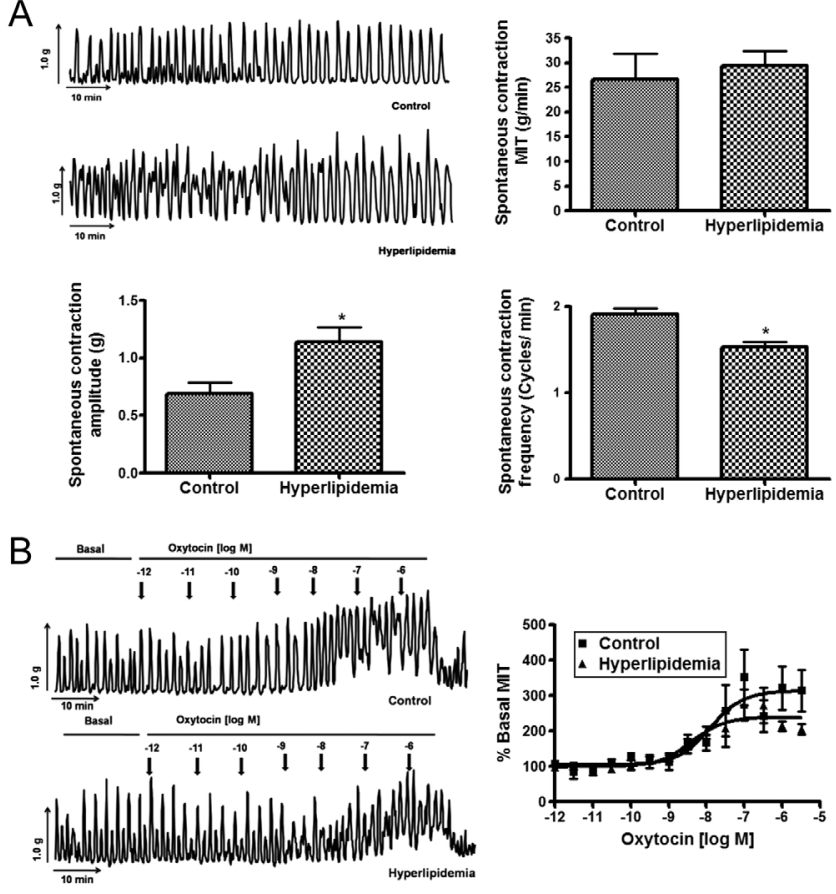

Figure 2 Representative tracings depict the effect of hyperlipidemia on the spontaneous uterine contractility (A) and the effect of oxytocin, added at 1 log unit interval on spontaneous uterine contraction (B). Spontaneous contractile MIT in control and hyperlipidemia groups was not significantly different although the amplitude and frequency differed (A). Values are means with S.E.M. represented by vertical bars. The data were analyzed by unpaired $t$-test. * indicates $P<0.05$ as compared to control; Line diagrams of oxytocin concentration-response in late pregnant uterus showing no statistical significance between the control and hyperlipidemic groups (B), Results are expressed as mean \pm S.E.M. Contractile response is expressed as the percentage of basal MIT of contractions. The data were analyzed by two-way ANOVA.

animals, whereas it was $85.97 \pm 4.46 \%$ in hyperlipidemic animals $(P=0.14) . \quad-\log \mathrm{EC}_{50}$ value, however, was decreased significantly by hyperlipidemia $(6.33 \pm 0.25$ vs $7.96 \pm 0.19$ in control, $P=0.0003)$. Moreover, the concentration-response to BRL-37344 was significantly inhibited in hyperlipidemia group $(P=0.0002)$.

\section{Effect of hyperlipidemia on forskolin-induced uterine relaxation}

To demonstrate any effect of HFHC diet on adenylyl cyclase pathway, we used an activator of adenylyl cyclase, forskolin. Forskolin $\left(10^{-11}-10^{-5} \mathrm{M}\right)$, added cumulatively to uterine strips produced a concentrationrelated relaxation. The relaxation response was significantly altered between the two groups in terms of $E_{\max }(66.20 \pm 5.22 \%$ vs $104.8 \pm 6.68 \%$ in control, $n=6$ each, $P<0.001)$ and $-\log \mathrm{EC}_{50}(8.25 \pm 0.27$ vs $7.49 \pm 0.20$ in control, $n=6$ each, $P=0.049$ ) (Fig. 4A). Moreover, the concentration-response to forskolin was significantly inhibited by hyperlipidemia $(P=0.0006)$.

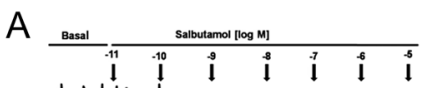
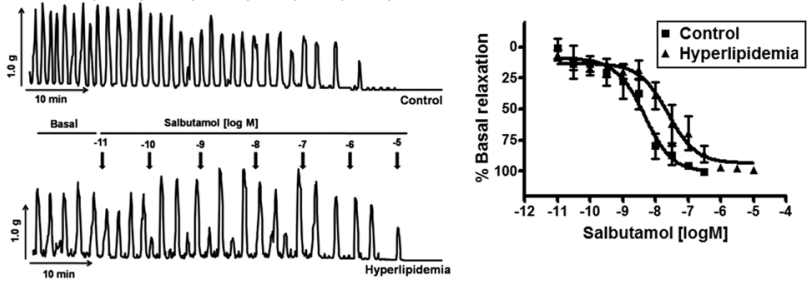

B
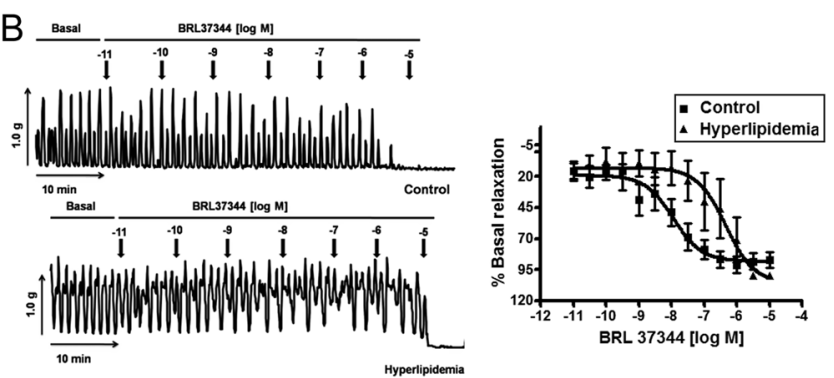

Figure 3 The effect of hyperlipidemia on exogenously added (A) salbutamol and (B) BRL37344 responses in longitudinal uterine strips on the 21 st day of gestation in rats. Values are means with S.E.M. represented by vertical bars. Relaxant responses are expressed as the percentage inhibition of basal MIT of contractions. The data were analyzed by two-way ANOVA.

\section{Effect of hyperlipidemia on $\beta$-adrenoceptor-stimulated cAMP content on the 21 st day of gestation}

We measured the basal, as well as $\beta$-adrenoceptor agoniststimulated CAMP content in uterine tissues (Fig. 5). The basal cAMP content was not affected $(P>0.05)$ by hyperlipidemia $(87.54 \pm 21.48 \%$ vs $100 \%$ in control, $n=4$ each) but the cAMP content in salbutamol $(1 \mu \mathrm{M}$; $149.9 \pm 15.48 \%$ vs $227.7 \pm 12.62 \%$ in control) and BRL$37344(10 \mu \mathrm{M} ; 109 \pm 9.07 \%$ vs $221 \pm 25.11 \%)$-stimulated tissues were significantly decreased, $P<0.01$.

\section{Effect of hyperlipidemia on Adrb2 and Adrb3 mRNA expressions on the 21st day of gestation}

As evident from real-time PCR study (Fig. 6A), Adrb2 and Adrb3 mRNA expressions were not altered by hyperlipidemia. In control group, Adrb2 mRNA expression in terms of $2^{-\Delta C T}$ value, was $0.29 \pm 0.03$ $(n=5)$. In hyperlipidemia, expression was not different $(P=0.33)$, with $2^{-\Delta C T}$ value of $0.45 \pm 0.15 \quad(n=5)$. Similarly, Adrb3 mRNA expression was not altered in hyperlipidemic group $(0.49 \pm 0.14$ vs $1.4 \pm 0.70$ in control, $n=5$ each, $P=0.24$ ).

\section{Effect of hyperlipidemia on mRNA expressions of Gnas and Gnai genes on the 21st day of gestation}

Figure 6B depicts the relative mRNA expressions of Gnas and Gnai genes in control and hyperlipidemic groups of rats. In control group, Gnas mRNA expression in terms 


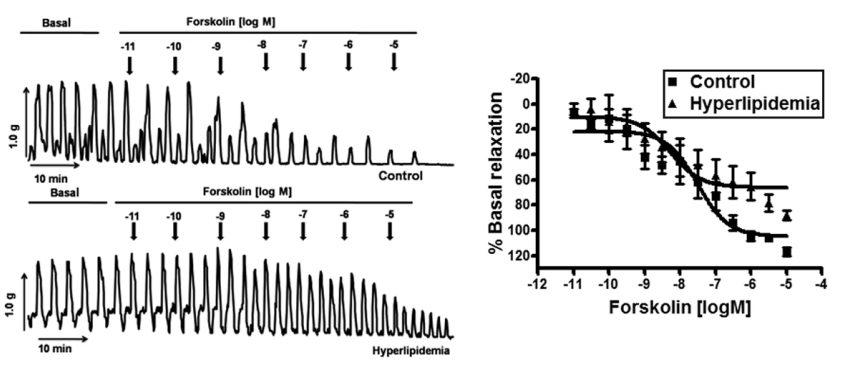

Figure 4 The effect of hyperlipidemia on forskolin response in 21-day pregnant rats. Values are means with S.E.M. represented by vertical bars. Relaxant responses are expressed as the percentage inhibition of basal MIT of contractions. The data were analyzed by two-way ANOVA.

of $2^{-\Delta C T}$, was $0.92 \pm 0.07 \quad(n=5)$. In hyperlipidemic group, mRNA expression of Gnas was $0.68 \pm 0.13(n=5$, $P=0.14)$. The inhibitory G-protein, Gnai expression was $0.11 \pm 0.05(n=5)$ in control group, whereas it was increased $(P=0.03)$ in hyperlipidemic group up to $0.30 \pm 0.05(n=5)$.
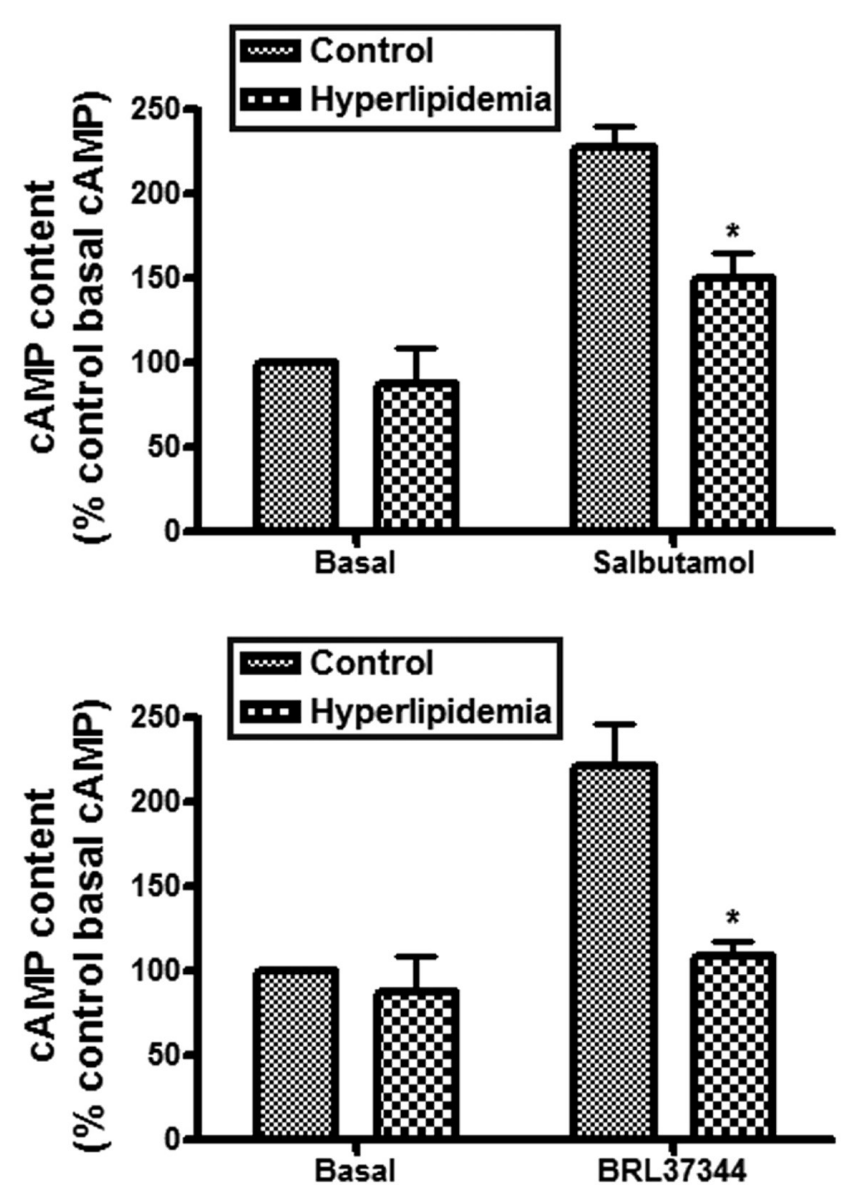

Figure 5 The effects of hyperlipidemia on basal and agonist-stimulated cAMP content. Salbutamol $(1 \mu \mathrm{M})$ and BRL37344 (10 $\mu \mathrm{M})$-stimulated CAMP contents were significantly lower in hyperlipidemia group. Values are means with S.E.M. represented by vertical bars. The data were analyzed by two-way ANOVA followed by Bonferroni post hoc test. * indicates $P<0.05$ as compared to control.
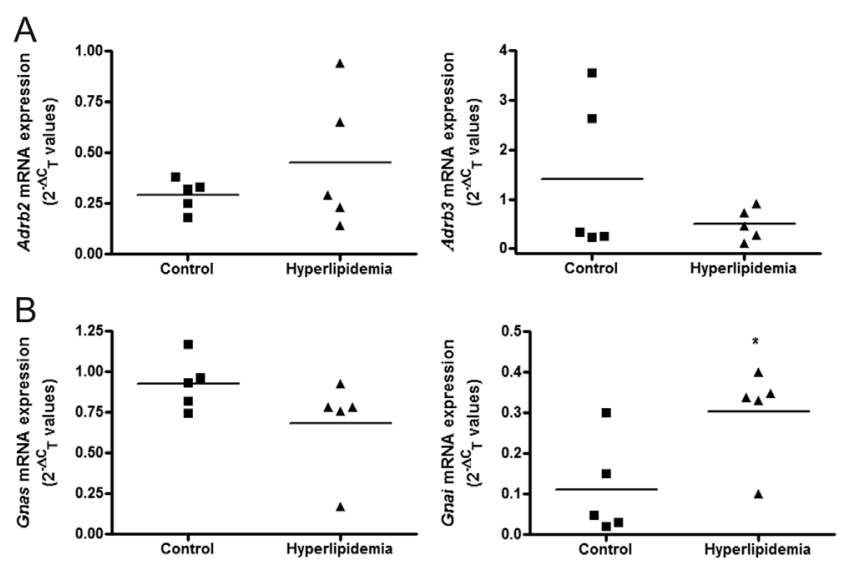

Figure 6 Effect of hyperlipidemia on mRNA expressions of Adrb2, Adrb3, Gnas and Gnai genes (A and B). Individual values were represented along with the means in a scattered plot. Unpaired $t$-test was used to compare between the two groups. Difference between control and hyperlipidemia was considered significant at the level of $P<0.05(*)$.

\section{Discussion}

The main observations of the present study are (1) the hyperlipidemic animals parturited earlier than the control animals though the overall spontaneous contractility in non-laboring uterus was not affected on gestation day 21. (2) Also, contractile response to oxytocin was not altered in hyperlipidemic animals, (3) But, potencies of $\beta$-adrenergic agonists salbutamol and BRL-37344 were significantly reduced in high fat-fed animals, (4) In addition, receptor-independent activator of adenylyl cyclase, forskolin elicited a reduced relaxant response in high-fat-fed animals, (5) Consistent with the functional studies, we observed a significant decrease in cAMP production by salbutamol and BRL-37344 and a significant increase in Gnai mRNA expression in hyperlipidemic animals.

Along with increased body weight and elevated lipids, the high-fat rat model exhibited increase in renal and peritoneal fats. Dyslipidemia particularly, hypertriglyceridemia in first and third trimester of pregnancy actually has been implicated to cause preterm labor in women (Mudd et al. 2012). Chen and Scholl (2008) have demonstrated the effect of elevated fatty acids on preterm labor outcome independent from the effects of BMI. It is speculated that proinflammatory effect of fatty acids, along with their oxidative properties, might contribute to at least a portion of spontaneous preterm births (Catov et al. 2014). So we attribute the pregnancy outcome in our model to the drastic increase in triglycerides besides cholesterol in serum and tissue.

However, we did not observe any change in mean integral tension of spontaneous uterine contractions which indicates that cholesterol and triglycerides accumulation in uterus has little effect on membrane 
depolarization, more specifically on L-type $\mathrm{Ca}^{2+}$ channel activation (Shmygol et al. 2007). Hyperlipidemia had no significant effect on oxytocin-induced contractions. However, a significant impairment in oxytocin-induced contractions had been observed in a mouse model with elevated levels of cholesterol irrespective of the levels of triglyceride (Padol et al. 2017). Our result may suggest that accumulation of triglycerides along with cholesterol in uterine tissue prevents cholesterolinduced attenuation of oxytocin response. On the other hand, the former finding is supported by a study in a similar obese rat model demonstrating no effect on oxytocin-induced contraction in non-laboring tissue (Muir et al. 2016). Nevertheless, these authors observed an increase in oxytocin receptor expression and paradoxical decrease in oxytocin-induced contraction in laboring uterine tissue. Continuous stimulation of oxytocin receptors may lead to desensitization of the receptors (Willets et al. 2009) during labor, hence, can lead to reduced oxytocin response.

We noticed that the potencies of both salbutamol and BRL-37344 were significantly reduced in hyperlipidemic animals. In a rat model of hypercholesterolaemia, $\beta$-adrenergic response was potentiated in detrusor smooth muscle (Bayrak et al. 2015). Acute treatment with simvastatin (a cholesterol synthesis inhibitor) inhibited the relaxant effect of salbutamol in porcine coronary artery (Uhiara et al. 2012). However, use of simvastatin for 2 days in ventricular cardiomyocytes exhibited negative inotropic and positive lusitropic effects (Pugh et al. 2014). $\beta$-adrenoceptors' abundance and activation throughout gestation keep the myometrium quiescent until parturition (Engstrøm et al. 1997). In obesity, we expected a potentiation of these responses to cause dysfunctional labor. However, in our model there was inhibition of these responses indicating it as one of the probable reasons of reduced gestational length. Since most related studies on $\beta$-adrenergic signaling in different tissues particularly myocardial tissues have assessed the effect of cholesterol alone under in vitro conditions (Odnoshivkina et al. 2017), it is difficult to speculate the effects of triglycerides from these studies. However, isoprenaline (nonselective $\beta$-adrenoceptor agonist) response in left ventricular papillary muscle was inhibited in obese Zucker rats compared to lean Zucker rats (Jiang et al. 2015). Similar impairment in $\beta$-adrenergic signaling was also observed in white adipocytes of suckling fa/fa Zucker rats (Mory et al. 2001).

Decrease in potencies of salbutamol and BRL37344 suggests either the decrease in $\beta$-adrenoceptors' expression or reduced signaling efficiency by these receptors in hyperlipidemic animals. We did not detect any change in mRNA expressions of $\beta_{2^{-}}$and $\beta_{3}$-adrenoceptors in hyperlipidemic animals although the possibility of downregulation of $\beta$-adrenoceptors by receptor-desensitizing enzymes (GRK and PK-A) cannot be ruled out by our data. Likewise, there may be reduced signaling efficiency through $\beta$-adrenoceptors in hyperlipidemic animals. In this condition, reduced signaling can occur due to alteration in ligand/effectors binding sites of the receptor (Hauser et al. 2017), restricted conformational variability favoring low affinity states of the receptor (Manna et al. 2016) or by altering various steps in signaling, independent of the receptor.

To elucidate the mechanism of reduced $\beta$-adrenergic response in high-fat-fed animals, we used a receptorindependent activator of adenylyl cyclase called forskolin. $E_{\max }$ of forskolin-induced relaxation was lowered in hyperlipidemic animals indicating alteration in downstream pathways like adenylyl cyclase in hyperlipidemic animals. Similar result was obtained in Zucker obese rats where forskolin response on inotropic effects in isolated papillary muscle was significantly decreased (Jiang et al. 2015). We also observed significant decrease in the uterine levels of agoniststimulated CAMP in hyperlipidemic animals, though the basal cAMP levels were not altered. Cholesterol depletion by methyl- $\beta$-cyclodextrin in adult cardiac myocytes significantly increases cAMP response to isoprenaline (Agarwal et al. 2011). On the other hand, cyclic AMP accumulation in response to isoprenaline was inhibited in cholesterol-enriched $\mathrm{CHO}-\mathrm{K} 1$ cells (Middleton et al. 2001). Decrease in isoprenaline ( $\beta_{2}-A R$ agonists)-stimulated adenylyl cyclase activity has been associated with a rapid and transient reduction of highaffinity receptors as well as increase in myometrial Gi $2 \alpha$ and Gi3 $\alpha$ proteins (Lécrivain et al. 1998).

Hyperlipidemia had no significant effect on the mRNA expression levels of $\beta_{2}$ and $\beta_{3}$ adrenergic receptors and Gs protein. However, it significantly increased the mRNA expression of Gi protein. Classically, $\beta_{2}-$ and $\beta_{3^{-}}$ adrenoceptors couple to the Gs protein that activates adenylyl cyclase signaling pathway. It is also known that both $\beta_{2}-A R$ and $\beta_{3}-A R$ subtypes couple to the $G i$ proteins that counteract the effect of the Gs proteins on cyclic AMP production (Soeder et al. 1999, Woo \& Xiao 2012). As regards to $\beta_{2}-A R$ in cardiac myocytes, phosphorylation of the receptor promotes Gi coupling and increases expression of PDE4, which both inhibit cardiac adrenergic signaling and compromise cardiac contractile function (Shi et al. 2017). Thus, increased mRNA expression of Gi protein may probably favor its coupling to $\beta$-adrenergic receptors in place of Gs protein to inhibit adenylyl cyclase pathway and impair relaxant responses in uterine smooth muscle. Moreover, significant amounts of $\mathrm{Gi}$ proteins remain associated with oxytocin receptors along with Gq proteins (Busnelli et al. 2012). Though the functional consequence of increase in transcription of $\mathrm{Gi}$ proteins is not known, their coupling to oxytocin receptors may also contribute to impaired uterine relaxation. 


\section{Conclusion}

Obesity is a metabolic condition that affects a number of organ systems including uterine smooth muscle. Increased cholesterol and triglycerides in the uterine tissue can inhibit $\beta$-adrenergic response during late gestation by increasing transcription of Gi proteins and decreasing CAMP content. Decrease in cAMP content has the potential to influence the therapy of preterm labor by $\beta$-adrenergic agonists used as uterine relaxants. However, further studies are required to verify the findings in clinical settings and also to delineate the roles of cholesterol and/or triglycerides in producing two different kinds of uterine dysfunction that is dysfunctional (prolonged) labor and premature labor.

\section{Declaration of interest}

The authors declare that there is no conflict of interest that could be perceived as prejudicing the impartiality of the research reported.

\section{Funding}

This work was funded by the Department of Biotechnology (DBT), Ministry of Science and Technology, Government of India, New Delhi.

\section{Author contribution statement}

S C performed most of the experiments, $P$ E, S G and $V \mathrm{~S}$ assisted in performing the experiments, S P acquired funds, conceptualized and designed the experiments, supervised the experiments, wrote the paper, M P analyzed and interpreted qPCR data and also provided some resources, $T \cup S$ analyzed and interpreted data, S K M reviewed and edited the work plan and the paper.

\section{Acknowledgements}

The Junior Research Fellowship (JRF) awarded to S C by the Indian Council of Agricultural Research (ICAR), New Delhi, is gratefully acknowledged. The authors are thankful to the Director, Indian Veterinary Research Institute, for providing necessary facilities.

\section{References}

Agarwal SR, MacDougall DA, Tyser R, Pugh SD, Calaghan SC \& Harvey RD 2011 Effects of cholesterol depletion on compartmentalized CAMP responses in adult cardiac myocytes. Journal of Molecular and Cellular Cardiology the $\mathbf{5 0}$ 500-509. (https://doi.org/10.1016/j. yjmcc.2010.11.015)

AlSaif S, Mumtaz S \& Wray S 2015 A short review of adipokines, smooth muscle and uterine contractility. Life Sciences 125 2-8. (https://doi. org/10.1016/j.lfs.2015.02.001)

Bayrak S, Balkanci ZD, Pehlivanoğlu B, Karabulut İ, Karaismailoğlu S \& Erdem A 2015 Does hypercholesterolemia affect the relaxation of the detrusor smooth muscle in rats? In vitro and in vivo studies.
Naunyn-Schmiedeberg's Archives of Pharmacology 388 761-771. (https://doi.org/10.1007/s00210-014-1060-7)

Busnelli M, Saulière A, Manning M, Bouvier M, Galés C \& Chini B 2012 Functional selective oxytocin-derived agonists discriminate between individual G protein family subtypes. Journal of Biological Chemistry 287 3617-3629. (https://doi.org/10.1074/jbc.M111.277178)

Catov JM, Bertolet M, Chen YF, Evans RW \& Hubel CA 2014 Nonesterified fatty acids and spontaneous preterm birth: a factor analysis for identification of risk patterns. American Journal of Epidemiology 179 1208-1215. (https://doi.org/10.1093/aje/kwu037)

Chanrachakul B, Matharoo-Ball B, Turner A, Robinson G, BroughtonPipkin F, Arulkumaran S \& Khan RN 2003 Reduced expression of immunoreactive $\beta 2$-adrenergic receptor protein in human myometrium with labor. Journal of Clinical Endocrinology and Metabolism $\mathbf{8 8}$ 4997-5001. (https://doi.org/10.1210/jc.2003-030692)

Chen X \& Scholl TO 2008 Association of elevated free fatty acids during late pregnancy with preterm delivery. Obstetrics and Gynecology $\mathbf{1 1 2}$ 297-303. (https://doi.org/10.1097/AOG.0b013e3181802150)

Chen Q, Zhang Y, Peng H, Lei L, Kuang H, Zhang L, Ning L, Cao Y \& Duan E 2011 Transient $\beta 2$-adrenoceptor activation confers pregnancy loss by disrupting embryo spacing at implantation. Journal of Biological Chemistry 286 4349-4356. (https://doi.org/10.1074/jbc.M110.197202)

De Heus R, Mol BW, Erwich JJH, Van Geijn HP, Gyselaers WJ, Hanssens M, Härmark L, Van Holsbeke CD, Duvekot JJ, Schobben FF et al. 2009 Adverse drug reactions to tocolytic treatment for preterm labor: prospective cohort study. BMJ 338 744. (https://doi.org/10.1136/ bmj.b744)

Engstrøm T, Bratholm P, Vilhardt H \& Christensen NJ 1997 Effect of pregnancy on rat myometrial $\beta 2$-adrenoceptor mRNA and isoproterenolinduced relaxation of isolated uterine strips. Journal of Endocrinology 153 393-399. (https://doi.org/10.1677/joe.0.1530393)

Gokul C, Parida S, Singh TU, Panigrahi M, Suhas KS, Soni K, Kesavan M, Srivastava V, Kumar TS \& Mahobiya A 2018 Lysophosphatidic acid enhances PGE2 to PGF2 $\alpha$ ratio and nitric oxide level in nonpregnant buffalo uterus. Theriogenology 120 47-55. (https://doi.org/10.1016/j. theriogenology.2018.07.014)

Hauser AS, Attwood MM, Rask-Andersen M, Schiöth HB \& Gloriam DE 2017 Trends in GPCR drug discovery: new agents, targets and indications. Nature Reviews: Drug Discovery 16 829-842. (https://doi. org/10.1038/nrd.2017.178)

Jiang C, Carillion A, Na N, De Jong A, Feldman S, Lacorte JM, BonnefontRousselot D, Riou B \& Amour J 2015 Modification of the $\beta$-adrenoceptor stimulation pathway in Zucker obese and obese diabetic rat myocardium. Critical Care Medicine 43 e241-e249. (https://doi.org/10.1097/ CCM.0000000000000999)

Lécrivain JL, Cohen-Tannoudji J, Robin MT, Coudouel N, Legrand C \& Maltier JP 1998 Molecular mechanisms of adenylyl cyclase desensitization in pregnant rat myometrium following in vivo administration of the $\beta$-adrenergic agonist, isoproterenol. Biology of Reproduction 59 45-52. (https://doi.org/10.1095/biolreprod59.1.45)

Lin XH, Wu DD, Li C, Xu YJ, Gao L, Lass G, Zhang J, Tian S, Ivanova D, Tang L et al. 2018 Maternal high triglyceride levels during early pregnancy and risk of preterm delivery: a retrospective cohort study. Journal of Clinical Endocrinology and Metabolism 104 1249-1258. (https://doi.org/10.1210/jc.2018-01372)

Lirussi F, Rakotoniaina Z, Madani S, Goirand F, Breuiller-Fouché M, Leroy MJ, Sagot P, Morrison JJ, Dumas M \& Bardou M 2008 ADRB3 adrenergic receptor is a key regulator of human myometrial apoptosis and inflammation during chorioamnionitis. Biology of Reproduction $\mathbf{7 8}$ 497-505. (https://doi.org/10.1095/biolreprod.107.064444)

Lirussi $F$, $\mathrm{O}^{\prime}$ Brien $\mathrm{M}$, Wendremaire M, Goirand F, Sago P, Dumas M, Morrison JJ \& Bardou M 2010 SAR150640, a selective $\beta 3$-adrenoceptor agonist, prevents human myometrial remodelling and activation of matrix metalloproteinase in an in vitro model of chorioamnionitis. British Journal of Pharmacology 159 1354-1366. (https://doi.org/10.1111/ j.1476-5381.2009.00616.x)

Manna M, Niemelä M, Tynkkynen J, Javanainen M, Kulig W, Müller DJ, Rog T \& Vattulainen I 2016 Mechanism of allosteric regulation of $\beta 2$-adrenergic receptor by cholesterol. elife $\mathbf{5}$ 18432. (https://doi. org/10.7554/eLife.18432)

Middleton A, Nury D, Willington SJ, Latif L, Hill SJ \& Middleton B 2001 Modulation by cellular cholesterol of gene transcription via the cyclic 
AMP response element. Biochemical Pharmacology 62 171-181. (https://doi.org/10.1016/s0006-2952(01)00641-4)

Mory G, Wiel M, Adli H, Diot-Dupuy F, Ferre P \& Bazin R 2001 Impaired $\beta$-adrenergic signaling pathway in white adipocytes of suckling fa/ fa Zucker rats: a defect in receptor coupling. International Journal of Obesity and Related Metabolic Disorders 25 1592-1598. (https://doi. org/10.1038/sj.ijo.0801811)

Mudd LM, Holzman CB, Catov JM, Senagore PK \& Evans RW 2012 Maternal lipids at mid-pregnancy and the risk of preterm delivery. Acta Obstetricia et Gynecologica Scandinavica 91 726-735. (https://doi. org/10.1111/j.1600-0412.2012.01391.x)

Muir R, Ballan J, Clifford B, McMullen S, Khan R, Shmygol A, Quenby S \& Elmes M 2016 Modelling maternal obesity: the effects of a chronic highfat, high-cholesterol diet on uterine expression of contractile-associated proteins and ex vivo contractile activity during labor in the rat. Clinical Science 130 183-192. (https://doi.org/10.1042/CS20150539)

Odnoshivkina YG, Sytchev VI \& Petrov AM 2017 Cholesterol regulates contractility and inotropic response to $\beta 2$-adrenoceptor agonist in the mouse atria: involvement of Gi-protein-Akt-NO-pathway. Journal of Molecular and Cellular Cardiology 107 27-40. (https://doi.org/10.1016/j. yjmcc.2016.05.001)

Padol AR, Sukumaran SV, Sadam A, Kesavan M, Arunvikram K, Verma AD, Srivastava V, Panigrahi M, Singh TU, Telang AG et al. 2017 Hypercholesterolemia impairs oxytocin-induced uterine contractility in late pregnant mouse. Reproduction 153 565-576. (https://doi. org/10.1530/REP-16-0446)

Parida S, Uttam Singh T, Ravi Prakash V \& Mishra SK 2013 Molecular and functional characteristics of $\beta 3$-adrenoceptors in late pregnant mouse uterus: a comparison with $\beta 2$-adrenoceptors. European Journal of Pharmacology 700 74-79. (https://doi.org/10.1016/j. ejphar.2012.11.048)

Pedzińska-Betiuk A, Modzelewska B, Jóźwik M, Jóźwik M \& Kostrzewska A 2011 Differences in the effects of $\beta_{2^{-}}$and $\beta_{3}$-adrenoceptor agonists on spontaneous contractions of human nonpregnant myometrium. Ginekologia Polska 82 918-924.

Pugh SD, MacDougall DA, Agarwal SR, Harvey RD, Porter KE \& Calaghan S 2014 Caveolin contributes to the modulation of basal and $\beta$-adrenoceptor stimulated function of the adult rat ventricular myocyte by simvastatin: a novel pleiotropic effect. PLOS ONE 9 e106905. (https:// doi.org/10.1371/journal.pone.0106905)

Rouget C, Breuiller-Fouché M, Mercier FJ, Leroy MJ, Loustalot C, Naline E, Frydman R, Croci T, Morcillo EJ, Advenier C et al. 2004 The human nearterm myometrial $\beta_{3}$-adrenoceptor but not the $\beta_{2}$-adrenoceptor is resistant to desensitisation after sustained agonist stimulation. British Journal of Pharmacology 141 831-841. (https://doi.org/10.1038/sj.bjp.0705616)

Rouget C, Bardou M, Breuiller-Fouché M, Loustalot C, Qi H, Naline E, Croci T, Cabrol D, Advenier C \& Leroy MJ $2005 \beta_{3}$-Adrenoceptor is the predominant $\beta$-adrenoceptor subtype in human myometrium and its expression is up-regulated in pregnancy. Journal of Clinical Endocrinology and Metabolism 90 1644-1650. (https://doi.org/10.1210/ jc.2004-0233)
Schmittgen TD \& Livak KJ 2008 Analyzing real-time PCR data by the comparative $C_{\mathrm{T}}$ method. Nature Protocols 3 1101-1108. (https://doi. org/10.1038/nprot.2008.73)

Sheng R, Chen Y, Yung Gee H, Stec E, Melowic HR, Blatner NR, Tun MP, Kim Y, Källberg M, Fujiwara TK et al. 2012 Cholesterol modulates cell signaling and protein networking by specifically interacting with PDZ domain-containing scaffold proteins. Nature Communications 31249. (https://doi.org/10.1038/ncomms2221)

Shi Q, Li M, Mika D, Fu Q, Kim S, Phan J, Shen A, Vandecasteele G \& Xiang YK 2017 Heterologous desensitization of cardiac $\beta$-adrenergic signal via hormone-induced $\beta A R / a r r e s t i n / P D E 4$ complexes. Cardiovascular Research 113 656-670. (https://doi.org/10.1093/cvr/cvx036)

Shmygol A, Noble K \& Wray S 2007 Depletion of membrane cholesterol eliminates the $\mathrm{Ca}^{2+}$-activated component of outward potassium current and decreases membrane capacitance in rat uterine myocytes. Journal of Physiology $\mathbf{5 8 1}$ 445-456. (https://doi.org/10.1113/ jphysiol.2007.129452)

Singh V, Ram M, Kandasamy K, Thangamalai R, Choudhary S, Dash JR, Kumar D, Parida S, Singh TU \& Mishra SK 2015 Molecular and functional characterization of TRPV4 channels in pregnant and nonpregnant mouse uterus. Life Sciences 122 51-58. (https://doi.org/10.1016/j. Ifs.2014.12.010)

Soeder KJ, Snedden SK, Cao W, Della Rocca GJ, Daniel KW, Luttrell LM \& Collins S 1999 The $\beta_{3}$-adrenergic receptor activates mitogen-activated protein kinase in adipocytes through a Gi-dependent mechanism. Journal of Biological Chemistry 274 12017-12022. (https://doi.org/10.1074/ jbc.274.17.12017)

Subczynski WK, Pasenkiewicz-Gierula M, Widomska J, Mainali L \& Raguz M 2017 High cholesterol/low cholesterol: effects in biological membranes: a review. Cell Biochemistry and Biophysics 75 369-385. (https://doi.org/10.1007/s12013-017-0792-7)

Uhiara CO, Alexander SP \& Roberts RE 2012 Simvastatin evokes an unpredicted inhibition of $\beta$-adrenoceptor-mediated vasodilatation in porcine coronary artery. European Journal of Pharmacology 690 158-163. (https://doi.org/10.1016/j.ejphar.2012.07.006)

Willets JM, Brighton PJ, Mistry R, Morris GE, Konje JC \& Challiss RA 2009 Regulation of oxytocin receptor responsiveness by $G$ protein-coupled receptor kinase 6 in human myometrial smooth muscle. Molecular Endocrinology 23 1272-1280. (https://doi.org/10.1210/me.2009-0047)

Woo AYH \& Xiao RP $2012 \beta$-Adrenergic receptor subtype signaling in heart: from bench to bedside. Acta Pharmacologica Sinica 33 335-341. (https://doi.org/10.1038/aps.2011.201)

Received 30 July 2019

First decision 5 September 2019

Revised manuscript received 2 November 2019

Accepted 7 November 2019 